\title{
Качан Ю.Д., Положенкова Е.Ю. \\ Интенсификация значимости технического образования в современной образовательной системе России: за и против
}

Институт сферы обслуживания и предпринимательства (филиал) ДГТУ

(Россия, Шахты)

doi: 10.18411/trnio-12-2021-296

\section{Аннотация}

В статье рассмотрены основные проблемы высшей школы, касаемые значимости технического образования. В рамках исследования был проведен опрос среди обучающихся технического факультета и сделаны соответствующие выводы.

Ключевые слова: техническое образование, высшие учебные заведения, гуманитарные направления, технократические ценности.

\section{Abstract}

The article deals with the main problems of higher education concerning the importance of technical education. As part of the study, a survey was conducted among students of the technical faculty and relevant conclusions were drawn. values.

Keywords: technical education, higher education institutions, humanities, technocratic

Данная статья посвящена проблеме возросшей значимости технического образования в современной образовательной системе России и некоторым социокультурным, социальнопсихологическим последствиям данного явления. Как известно, сфера высшего образования тесно связана с определёнными социальными запросами общества. Это могут быть экономические, политические, социальные, духовно-мировоззренческие потребности. Данное обстоятельство, как правило, определяет приоритеты в выделении государством бюджетных мест для подготовки специалистов по тем или иным специальностям или направлениям [1].

Ниже помещён рисунок, на котором можно заметить некоторые не слишком значительные изменения количества бюджетных мест в высших учебных заведениях за период с 1964 года по 2016 год. Вместе с тем приоритеты в распределении бюджетных мест для подготовки специалистов по тем или иным специальностям или направлениям значительно менялись. Так, в конце XX - начале XXI века экономический кризис в России привел к необходимости подготовки значительного числа новых специалистов в данной сфере [2]. Следовательно, количество бюджетных мест на экономические направления было гораздо выше, чем на технические специальности.

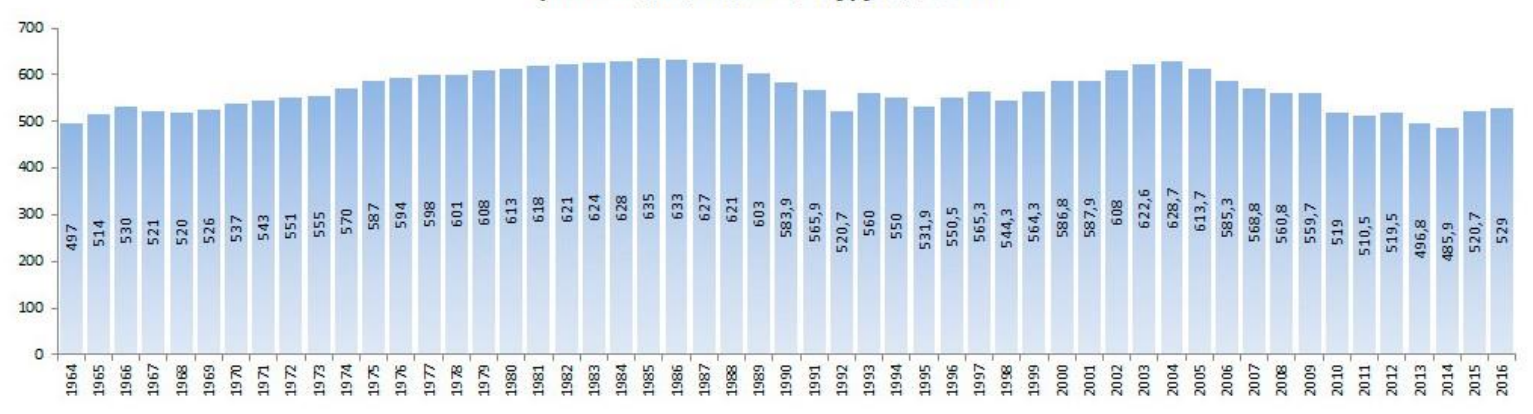

Рисунок 1. Количество бюджетных мест в ВУЗах 
В последние годы в связи с потребностями современного этапа научно-технического прогресса, интенсивного развития новых технологий получение технического образования становится всё более приоритетным[3]. Соответственно количество бюджетных мест в технических вузах заметно увеличивается по сравнению с социально-гуманитарными направлениями.

Возникает проблема, связанная с тем, что человек вынужден выбирать для дальнейшего обучения техническую специальность, из-за необходимости получения образования и ограниченности материальных возможностей. Следовательно, человек теряет свое предназначение в жизни, так как не имеет склонности к техническим наукам и возможно в гуманитарной сфере добился бы больших успехов.

В рамках исследования нами был проведен опрос, генеральную совокупность которого составили обучающиеся очной и очно-заочной форм обучения факультета «Техника и технологии» ИСОиП (филиала) ДГТУ в г. Шахты численностью 3188 человека. Объем выборки при доверительной вероятности 85\% и доверительном интервале 5\% был рассчитан по формуле и составил 195 респондентов. Целью опроса являлось выявление предрасположенностей к гуманитарным наукам студентов технического факультета. В опросе приняли участие обучающиеся всех курсов и всех направлений факультета, процентное соотношение изображено на диаграмме.

\section{Распределение респондентов по направлениям,\%}
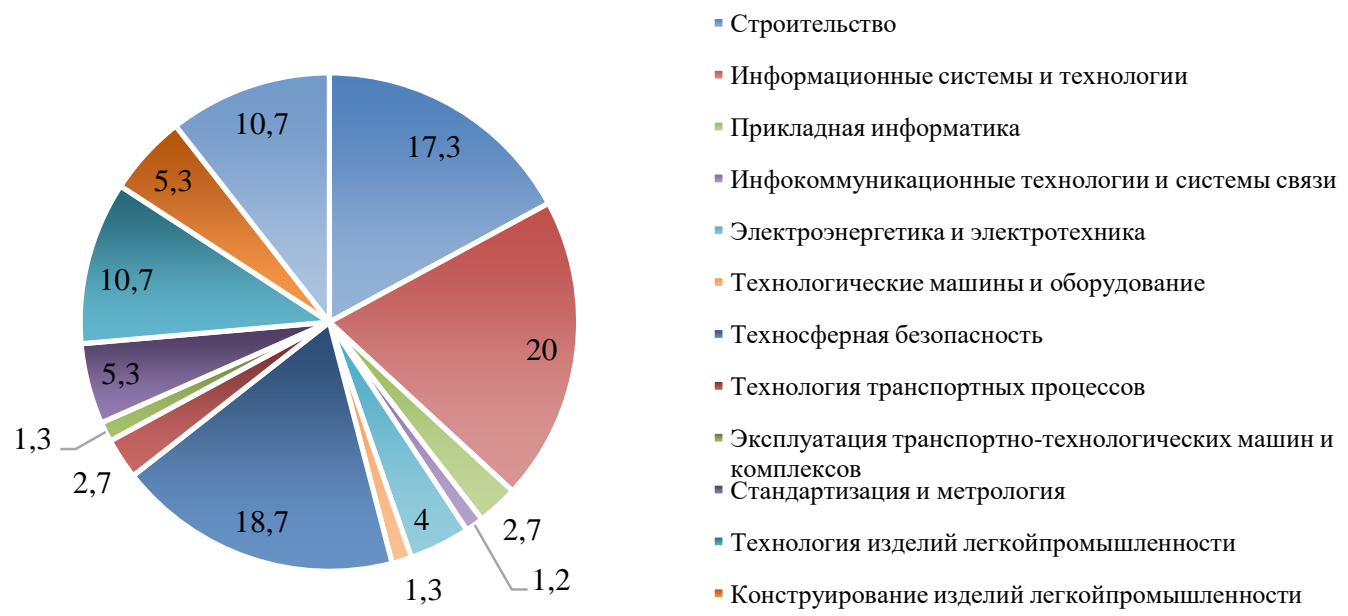

Рисунок 2. Диаграмма распределения респондентов по направлениям

На вопрос к какому типу Вы себя относите, 42,7 \% опрошенных ответили, что считают себя гуманитариями, а следовательно, могут быть не заинтересованы в своем обучении и дальнейшей деятельности по специальности. Возможно, эта часть обучающихся обучаются в вузе для формального получения диплома о высшем образовании.

Распределение ответов на следующий вопрос представлено на диаграмме.

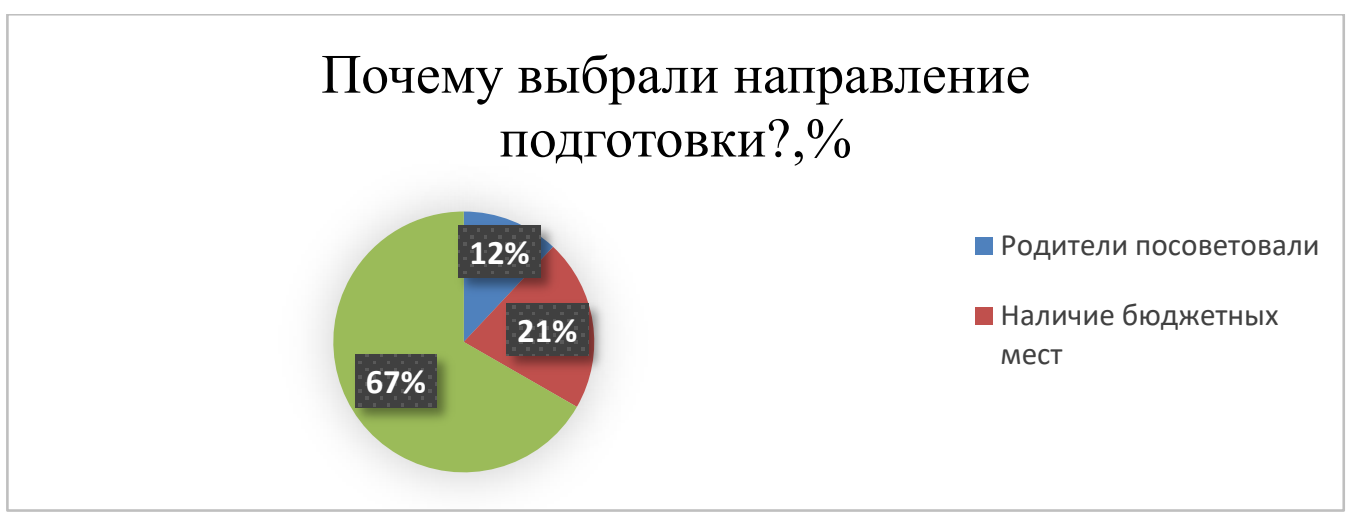

Рисунок 3. Диаграмма распределения ответов 
$21 \%$ обучающихся выбрали данное направление только из-за наличия достаточного количества бюджетных мест на техническом факультете, а также из-за повышения цен на обучение на гуманитарных направлениях. По совету родителей действовали $12 \%$ респондентов, данный ответ может свидетельствовать о незаинтересованности в своей профессии и дальнейшей деятельности в специальности.

На вопрос «Как Вы считаете, сможете ли Вы в будущем реализовать себя в выбранной профессии?» 84\% уверены, что смогут реализовать себя в данной профессии, что может свидетельствовать о том, что выбранная профессия является способом заработка, а не жизненным призванием, что может привести к профессиональной деформации и в дальнейшем выгоранию. 17,3\% не планируют работать по выбранной специальности, что может говорить о кадровой нехватке специалистов технических специальностей.

Нам представляется, что результаты проведённого исследования приводят к выводу о том, что необходима большая сбалансированность в распределении бюджетных мест между техническими и социально-гуманитарными направлениями. Одной из основных целей развития современной системы высшего и среднего образования должна стать гармония технократических и гуманистических ценностей [4]. Научно-технический прогресс невозможен без гуманитарной составляющей, которая обеспечивает сохранение и передачу нравственных и духовных принципов человечества и является фундаментом развития инженерной деятельности [5]. Высшие учебные заведения также должны быть заинтересованы в этом гармоничном соотношении, обеспечение которого будет способствовать не только подготовке профессионалов высокого уровня, но и мировоззренчески зрелых, социально ответственных личностей.

$$
* * *
$$

1. Байбородова Л. В., Чернявская А. П. Методология и методы научного исследования. Учебное пособие. М.: Юрайт. 2018. 222 с.

2. Вонсовский С. В. Современная естественно-научная картина мира. - М.: Регулярная и хаотическая динамика, Институт компьютерных исследований. 2006. 680 c.

3. Дрещинский В. А. Методология научных исследований. Учебник для бакалавриата и магистратуры. - M.: Юрайт. 2019. 274 с.

4. Склярова Е.А., Ерофеева Г.В., Лидер А.М. ПРОБЛЕМЫ ТЕХНИЧЕСКОГО ОБРАЗОВАНИЯ // Международный журнал экспериментального образования. - 2013. - № 11-1. - C. 126-128; URL: https://expeducation.ru/ru/article/view?id=4446 (дата обращения: 28.11.2021).

5. Перехожева Е.В. Формирование профессиональной компетентности студентов технических вузов на основе междисциплинарной интеграции / Е.В. Перехожева / Дис. ... кандидата педагогических наук: 13.00.08. Чита, 2012. -208 c.

\section{Сайганова Е.В., Демиденко А.В. Актуальные проблемы молодой семьи}

Саратовский национальный исследовательский государственный университет им. Н.Г. Чернышевского doi: 10.18411/trnio-12-2021-297

(Россия, Саратов)

\section{Аннотация}

Молодая семья как один из важнейших социальных институтов занимает ключевое место в российской действительности. Данная статья раскрывает проблемы наиболее актуальные для современных семей. Основная проблематика сводится к социальнопсихологическим критериям отклонений в молодой семье. Рассмотрены проблемы, ведущие к семейному неблагополучию. Отмечено, что важную роль в решении проблем семьи играет государство и общество, целостность малой группы зависит от самих супругов, их заинтересованности в сохранении брака.

Ключевые слова: семья, молодая семья, молодёжь, брак, проблемы молодой семьи. 